\title{
Hacia la mejora del secado mecánico del café en Colombia
}

\author{
Jhony Mauricio GutiérRez FlóReZ ${ }^{1}$ \\ Henry Copete López ${ }^{2}$
}

\section{Resumen}

En este trabajo se presenta una revisión y análisis del estado del arte de las tecnologías de secado mecánico de café y potenciales acciones para incrementar la eficiencia. Además, se plantea la importancia de utilizar el alcohol carburante obtenido a partir de los subproductos del proceso del beneficio húmedo del grano, pulpa y mucílago, como una opción para la mejora en la emisión de partículas y dióxido de carbono a la atmosfera con respecto a los sistemas de secado mecánico convencionales en Colombia.

\section{Palabras Clave}

Café, Secado mecánico, Alcohol carburante.

\section{Alostract}

This work is a review and analysis of the state of art of mechanical technologies for the coffee drying and potential actions to increase the efficiency. Also, it describes the importance to use alcohol as fuel, which could be obtained from subproducts of the humid benefit

1 Ingeniero Mecánico y estudiante de Maestría en Gestión Energética Industrial. Grupo GITER. Instituto Tecnológico Metropolitano. Investigador. jhonygutierrez@ itm.edu.co.

2 M.Sc. Ingeniero Mecánico. Grupo GITER. Instituto Tecnológico Metropolitano. Docente Investigador. henrycopete@itm.edu.co. 
process of the grain, pulp and mucilage; this could be an option to improve carbon dioxide and particles emissions in comparison with conventional mechanics drying systems in Colombia.

\section{Key Words}

Coffee, Mechanical drying, Alcohol fuel. 


\section{INTRODUCCIÓN}

El beneficio del café es un proceso mediante el cual se obtiene café pergamino seco a partir de café cereza, en una relación en masa de 1 a 5 aproximadamente (Montilla, 2006) y resultando como subproductos de este proceso la pulpa y el mucílago (Montilla et al, 2008a; 2008b). El proceso comprende una serie de operaciones como clasificación, lavado, despulpado, remoción de mucílago y secado (Oliveros et al, 2007). De todas sus etapas la de mayor relevancia es el secado, que tiene como finalidad disminuir el contenido de humedad del café de $53 \%$ en base húmeda a un rango que oscile entre el $10 \%$ y $12 \%$ de humedad, apto para su comercialización (Roa et al, 1999).

El secado asegura un mayor beneficio económico al productor debido a que el producto seco sufre poco o ningún deterioro si es bien almacenado, permite la conservación de la semilla por largos períodos de tiempo conservando su poder de germinación y adquiere un mayor valor agregado si se empaca al consumidor (Alvarado, 2004). La comercialización del café pergamino húmedo trae consigo daños irreparables para la calidad final del producto, afectando finalmente sus características en tasa y modificando sus propiedades organolépticas como sabor suave y amargor moderado (Puerta, 2008a; 2008b).

En Colombia el secado del café se ha realizado tradicionalmente mediante dos métodos: el secado solar y el secado mecánico, existiendo la necesidad de realizar investigaciones buscando que estos procesos cada día sean más eficientes y menos contaminantes desde el instante en que se diseñan los equipos hasta la operación y mantenimiento de los mismos (Gutiérrez, 2008).

El secado mecánico históricamente se ha realizado con diferentes combustibles como el carbón mineral, combustibles derivados del petróleo y subproductos del proceso como el cisco o cascarilla del café, este último es considerado el combustible más económico (Oliveros et al, 2009), pero presenta fuertes impactos ambientales 
principalmente por la emisión de partículas y $\mathrm{CO} 2$ que son mayores cuando se utilizan combustibles sólidos.

La Federación Nacional de Cafeteros de Colombia ha venido realizando investigaciones en el proceso de beneficio de café con las cuales se han logrado desarrollos importantes como el módulo de beneficio ecológico de café y manejo de subproductos, el cual logra disminuir en más del $90 \%$ la contaminación producida por este proceso y se pueden aprovechar los subproductos provenientes de él (Fajardo \& Sanz, 2004).

Los resultados de investigaciones realizadas en el Centro Nacional de Investigaciones de Café, por (Calle, 1951) y recientemente por (Rodríguez, 2007), han demostrado que los residuos del beneficio del café como la pulpa y el mucílago se pueden utilizar como fuentes para la obtención económica de etanol anhidro. Tal afirmación se basa en el alto contenido que presentan dichos subproductos en azúcar, base para la producción de etanol. De hecho, los niveles de azúcar apreciados en éstos son incluso mayores que en otros vegetales utilizados para producir etanol combustible, como es el caso del maíz, pues de una tonelada de café cereza se podrían obtener hasta 19,24 litros de etanol.

Este alcohol se podría utilizar para otros procesos en la producción del mismo grano, además, es una solución factible en la búsqueda de fuentes de energías renovables y sostenibles con menor impacto ambiental que las utilizadas actualmente en el secado de los granos, con esto el sector cafetero estaría adicionando mayor valor agregado al proceso.

En este contexto, los autores consideran pertinentes las oportunidades de investigación y desarrollo de nuevas tecnologías eficientes para el sacado del café. Esta revisión hace parte del trabajo de investigación titulado "Secado de café con empleo de alcohol carburante obtenido de los subproductos del proceso de beneficio húmedo" de la Maestría en Gestión Energética Industrial del Instituto Tecnológico Metropolitano. 


\section{SeCAdO MECÁNICO del CAFÉ}

En Colombia el secado del café se ha realizado tradicionalmente mediante dos métodos, el secado solar y el secado mecánico. En el primero se aprovecha la entalpía del aire y la radiación solar para sustraer la humedad del grano (Buitrago, 2008; Jurado, 2008), es recomendado para fincas con producciones anuales inferiores a $2.500 \mathrm{~kg}$ con una duración entre 7 Y 15 días dependiendo de las condiciones atmosféricas, lo que lo hace un método totalmente dependiente del clima, con la ventaja de ser económico, pero con dos grandes desventajas debido a que la época de cosecha coincide con la época de lluvias incrementando el tiempo de secado y que sólo puede utilizarse en fincas de pequeña producción, en bajo flujo de cosecha para fincas medianas y muy pocas veces en fincas de alta producción, porque de utilizarse se necesitaría de extensas áreas de secado, ya que la altura máxima de capa recomendada es de 3 cm (Oliveros et al, 2006).

En el secado mecánico se utiliza una fuente externa de calentamiento para aumentar la temperatura del aire hasta $50^{\circ} \mathrm{C}$ e impulsarlo por un ventilador, generalmente centrífugo, a través de la capa o las posibles capas de grano provistas en las cámaras de secado y presecado, con una altura máxima por capa de $35 \mathrm{~cm}$ (Oliveros et al, 2009), hasta que se seque por extracción de humedad libre y difusión de humedad. Cuando la presión de vapor del agua en el grano es mayor que la presión de vapor del aire, ocurre la difusión de humedad o transferencia de masa desde el grano hacia el aire y viceversa, este proceso puede suceder hasta que el aire se sature y aumente su contenido de humedad relativa al 100\%, (González, 2008).

Entre los años 60 y 70's el secador mecánico más popular en Colombia era el tipo Guardiola, este secador como el presentado en la Figura 1, posee un gran cilindro como cuerpo que gira continuamente con los granos de café en su interior, levantándolos hasta dejarlos caer por gravedad desde la parte superior, utilizando palas metálicas empotradas en la parte interna del cilindro. La 
transferencia de calor hacia los granos de café, se produce cuando éstos chocan con el aire caliente que entra al secador a través de un tubo perforado, coaxial al eje del cilindro y para facilitar la evacuación del aire húmedo también eran perforadas las paredes externas del cilindro.

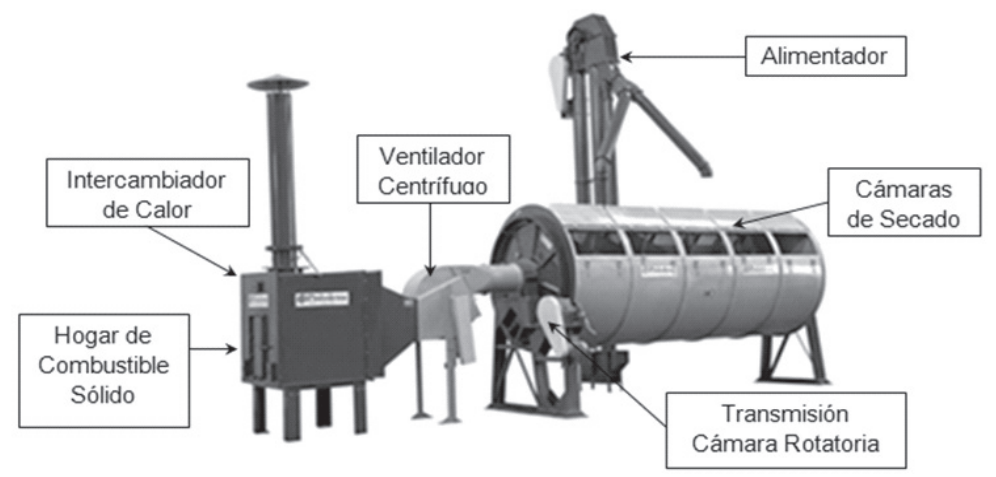

Figura 1. Secador Tipo Rotativo "Guardiola". Adaptado de (Pinhalense, 2009)

Este secador es recordado por la uniformidad en la humedad final que presentaba el café obtenido de él, lo que se traducía en una muy buena calidad, ya que todos los granos recibían casi el mismo tratamiento térmico por el hecho de que ellos se movían continuamente durante todo el proceso de secado. No obstante, estos secadores fueron sustituidos por los secadores de capa estática o silo secador, como resultado de varias investigaciones desarrolladas en este campo.

La razón fundamental por la cual se cambiaron los secadores tipo Guardiola por los secadores de capa fija, fue estrictamente por consideraciones prácticas y económicas. De hecho, la inversión económica inicial para adquirir estos últimos secadores es muy inferior comparada con la inversión para los secadores del primer tipo, y aún mejor, los materiales para construirlos son propios de las regiones cafeteras reduciendo los costos de construcción y mantenimiento.

El secado mecánico en Colombia utilizando silos secadores de capa estática, se realiza desde el año 1968, como resultado de 
varias investigaciones desarrolladas por la disciplina de Ingeniería Agrícola de Cenicafé, para ello, se cumple el mismo principio de calentar el aire, el cual debe vencer la resistencia al paso de aire o presión estática que producen la masa de café a secar depositada en una cámara o silo y los equipos que conforman el sistema. El tiempo de secado está comprendido entre 18 a 30 horas, sin que las condiciones climatológicas lo afecten enormemente, comparado con el secado solar. Para conservar los estándares de calidad del café (Puerta, 2003; 2006a; 2006b), se deben utilizar equipos de combustión indirecta los cuales no permiten que los gases de combustión se mezclen con el aire de secado para evitar la contaminación del producto, es recomendado para producciones anuales superiores a 2,5 toneladas (Oliveros et al, 2009), situación que no ocurre en el secador mostrado en la Figura 2.

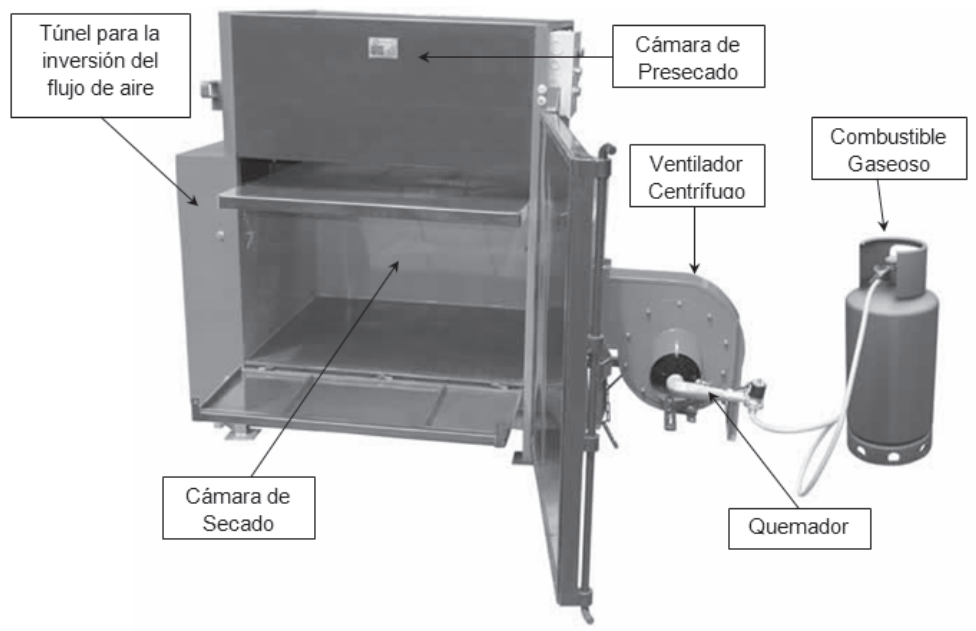

Figura 2. Componentes de un Secador mecánico. Adaptado de (Estrada, 2009)

En general los secadores mecánicos constan de cuatro componentes principales: la cámara de secado y presecado, ventilador, intercambiador de calor y el sistema de combustión. A continuación se describe cada uno de ellos con sus principales parámetros de funcionamiento. 


\subsection{Cámaras de secado}

operando adecuadamente y teniendo un buen sistema de ventilación que cumpla con los caudales de aire necesarios, se puede obtener un secado de buena calidad que cumpla con las normas para la comercialización del café (Orozco \& Bedoya, 2007). Esto no siempre se cumple por varias razones técnicas y de operación, las cuales no siempre conducen el proceso en forma satisfactoria, ya que continuamente se presentan problemas que concluyen en la no uniformidad final de la humedad del café.

En los primeros secadores de capa estática, desarrollados en los años 60's se presentaban altos gradientes de humedad, con diferencias hasta de $13 \%$ para una misma capa de granos. Por eso, con el fin de uniformizar la humedad final del producto en los secadores de café de capa estática, se invirtió la dirección del flujo del aire de secado en el silo secador de capa estática, atravesando la capa de granos en dos direcciones, de arriba hacia abajo y viceversa como se muestra en la Figura 3 a). Posteriormente, se pensó en la disminución de los costos de adquisición de estos equipos y se obtuvo un nuevo tipo de secador llamado secador vertical de 2 pisos, generando un secador más sencillo que el anterior como se muestra en la Figura 3 b). Este secador es más económico porque ocupa menos área y porque se disminuyó el número de compuertas para invertir la dirección del flujo del aire, sólo de abajo hacia arriba para las cámaras de presecado y en las dos direcciones en la cámara de secado. La otra solución para tratar de mejorar los problemas de desuniformidad en la humedad final del café, fue adicionarle una nueva capa, un nuevo piso al secador vertical de 2 pisos, dando paso al secador de 3 pisos o tres capas con inversión del flujo del aire de secado sólo en el piso inferior como puede observarse en la Figura $3 \mathrm{c}$ ).

Este último diseño de cámaras de secado facilita, en parte, la dificultad de obtener café uniforme y es hoy el secador con más ventajas porque es económico y tiene óptimos resultados si se opera con capas de café suficientemente delgadas de $25 \mathrm{~cm}$ por cámara de secado y un caudal de aire recomendado de $100 \mathrm{~m} 3 / \mathrm{min}$ por 
tonelada de café pergamino seco (Roa, 2004). Además, bajando las capas de grano ordenadamente y finalmente realizando las inversiones del aire en la cámara de secado, se puede obtener café con una humedad dentro del rango deseado para su comercialización.

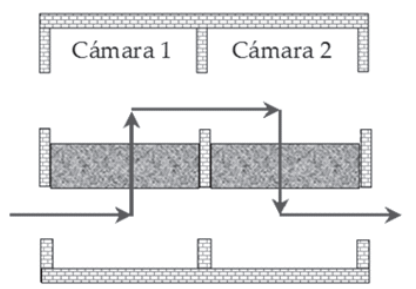

a)

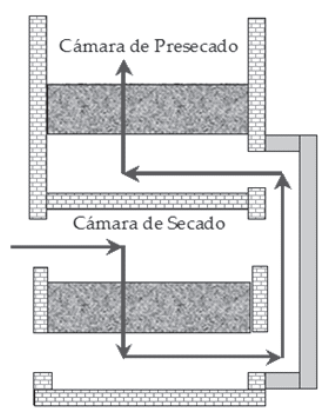

b)

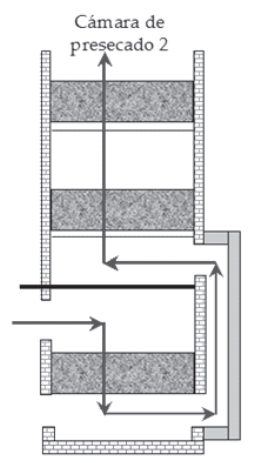

c)

Figura 3. Cámaras de secado de capa fiJa. Adaptado de (Gutiérrez, 2008)

Otra solución para disminuir los gradientes de humedad, es tener cámaras de secado cilíndricas en las cuales se adapta un sistema que permite revolver el café en su interior por medio palas agitadoras acopladas a un eje central que atraviesa las cámaras de secado queriendo volver al principio del secador Guardiola. Con este tipo de cámaras de secado con rotación manual o mecánica, se disminuye la posible aparición de frentes de secado en la capa de granos de café, pero se dificulta en parte el proceso productivo, porque se presentan granos mordidos o trillados dentro de las cámaras de secado, los cuales son catalogados como uno de los catorce defectos del café.

\subsection{Ventiladores}

Los ventiladores más apropiados para el acondicionamiento de productos agrícolas son los ventiladores centrífugos porque son de alto rendimiento y trabajan a altas presiones. 
Estos dispositivos son considerados el corazón del secador mecánico porque de él depende que el sistema tenga el caudal de aire necesario a la presión requerida para satisfacer las pérdidas de presión estática de cada componente del sistema: intercambiador de calor, capa de granos de café, ductos y compuertas para eventuales cambios en la dirección del flujo de aire.

El secado mecánico aprovecha las propiedades físicas del café, para evitar exceder los requerimientos de potencia mecánica en el motor que acciona el ventilador ya que su espacio intergranular es amplio $45 \%$ del volumen total (espacio libre entre granos de café para el paso del aire de secado) y posee una gran área de la superficie de los granos, $780 \mathrm{~m} 2$ por cada $\mathrm{m} 3$ de café pergamino seso, facilitando el paso del aire de secado a través de los granos y permitiendo el intercambio de energía térmica y de humedad.

De todos los factores que inciden en el secado mecánico el de mayor peso es la correcta selección e instalación del ventilador; de esta manera, es necesario determinar con exactitud el paso del caudal específico de aire de secado a través de la masa de café que se desea secar. El valor recomendado es de $100 \mathrm{~m} 3 / \mathrm{min}$ por tonelada de café pergamino seco (Roa, 2004), ya que este flujo de aire caliente es el encargado de suministrarle la energía térmica a las capas de café para que el proceso de evaporación se inicie y se pueda evacuar el vapor de agua que resulta.

Económicamente es rentable controlar el caudal de aire de secado entregado por el ventilador, pues un flujo de aire deficiente en el sistema de secado, haría que los granos resultaran finalmente con altas discrepancias en el contenido final de humedad, trayendo consigo granos flojos con humedad superior al $14 \%$ o granos sobresecos con humedad menor al 10\%, incurriendo en 2 de los 14 defectos del café e incrementando el tiempo de secado. En el caso contrario, si el caudal de aire es mayor al recomendado, habría exceso de energía térmica mal aprovechada, lo cual incrementaría la demanda de potencia del ventilador, aumentando los costos de producción por secado y haciendo el proceso no tan atractivo para el productor. 
La otra variable de importancia es la pérdida de presión estática que se da con el paso del aire a través de la masa de granos de café depositada en las cámaras del secador. Por medio de trabajos experimentales desarrollados (Roa et al, 1999), se pudo plantear una ecuación en función de la humedad del grano, con la cual se puede determinar el caudal específico de secado como función de la pérdida de presión específica para café pergamino seco.

$$
\frac{Q}{A}=(9,523-0,0476 M)\left|\frac{\Delta P}{\Delta L}\right|^{0,676}
$$

Donde:

$Q$ : Caudal de aire, $\left(\mathrm{m}^{3} / \mathrm{min}\right)$

$A$ : Área transversal al flujo de café, $\left(\mathrm{m}^{2}\right)$

$M$ : Contenido de humedad del café, (\%)

$\Delta P$ : Caída de presión en secciones distantes en L, (cm c.a.)

$\Delta L$ : Distancia entre mediciones de la pérdida de presión, (m)

Despejando la pérdida de presión específica de la ecuación 1, se puede determinar la presión estática que debe generar el ventilador en el sistema sólo para que el aire de secado atraviese la capa de granos de café que se desea secar, sin tener en cuenta las pérdidas de presión que generan los demás componentes del sistema.

$$
\frac{\Delta P}{\Delta L}=\left|\frac{\frac{Q}{A}}{9,523-0,0476 M}\right|
$$

Para el diseño de ventiladores centrífugos existen varias metodologías y algoritmos de diseño como el aplicado por (Díaz, 1994) y recientemente por (Gutiérrez, 2008), como una herramienta de diseño por (Bedoya, 2007) el cual sigue la metodología propuesta por (Orozco, 1995). Este algoritmo utiliza un método iterativo que combina los criterios de varios autores como (Masana, 1966; 
Church, 1975; Osborne, 1982). También explica cuidadosamente los cálculos necesarios para establecer las dimensiones del rotor, la voluta, la transmisión de potencia (Romero, 1998), entre otras a partir de las especificaciones de diseño. Las curvas características de los ventiladores centrífugos se pueden determinar utilizando procedimientos reportados por (Orozco, 1996) o para el caso específico del café siguiendo la metodología descrita por (Gutiérrez, 2008).

Gran parte de los ventiladores centrífugos utilizados para el secado del café en el país están siendo construidos en talleres rurales, empleando plantillas existentes de modelos elaborados con anterioridad, los cuales no garantizan las condiciones de presión estática y caudal de aire requeridas en los sistemas y reportados en la Figura 4, trayendo consigo no tan buenos resultados, además, éstos no satisfacen las características geométricas de un diseño apropiado, por lo que de allí se desprenden todos los problemas de funcionamiento los cuales van en detrimento de la eficiencia total del proceso.

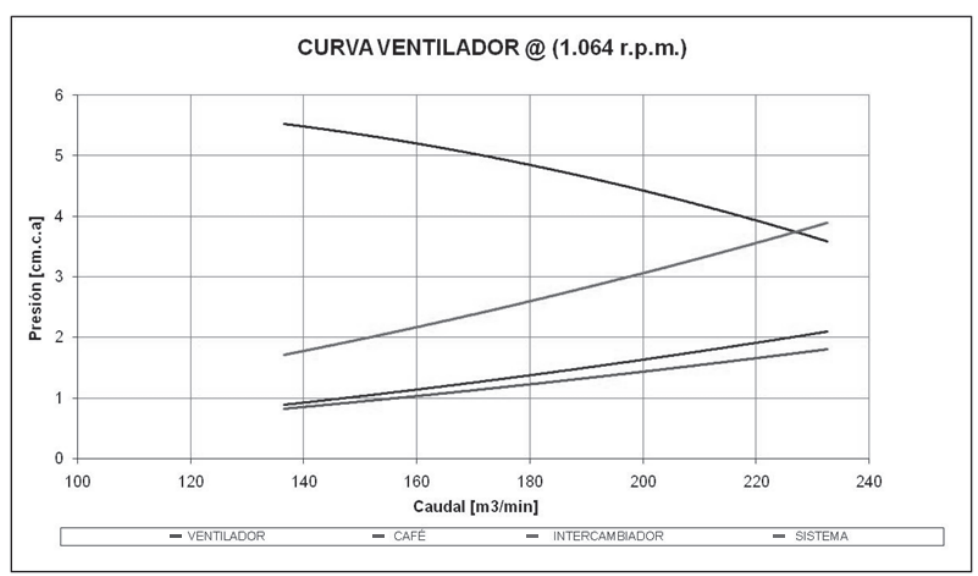

Figura 4. Curva caracteristica de un ventilador en un sistema de secado. Fuente (GUTIÉRREZ 2008) 
Con la metodología de diseño y construcción para ventiladores centrífugos utilizados en el secado mecánico del café desarrollada por (Gutiérrez, 2008) en Cenicafé, se logró una reducción en el costo de adquisición de éstos dispositivos mayor al 40\%, cabe resaltar que los ventiladores construidos tienen una eficiencia mayor al $63 \%$, valor que logran muy pocos ventiladores utilizados en esta labor. Para mejorar la eficiencia neumática de los ventiladores construidos, esta metodología utiliza un algoritmo de diseño mediante un aplicativo en Excel, con 18 variables de entrada, entre ellas, las más importantes: caudal y presión estática, el cual mediante iteraciones entrega 64 variables de salida, entre las que se destacan, la velocidad de giro y la potencia del motor, como todas las dimensiones de las piezas del ventilador; con estas dimensiones es parametrizado un prototipo digital en el software CAD Inventor, donde se obtienen los planos, para luego realizar un análisis de elementos finitos y determinar el material y los espesores respectivos.

\subsection{Intercambiadores de calor}

los Intercambiadores de calor utilizados actualmente para secado mecánico del café tienen un bajo nivel de eficiencia, con valores desde $30 \%$ para los equipos construidos artesanalmente en mampostería por talleres rurales hasta $60 \%$ para los dispositivos fabricados por la industria nacional. Ambos tipos de intercambiadores de calor están construidos con materiales diversos, presentan diferentes geometrías y utilizan varios combustibles entre los que se destacan: el cisco, el carbón mineral, el coque, el ACPM, el gas natural o el gas propano (González, 2008).

Estos dispositivos también presentan una baja eficiencia neumática, debido a los diferentes diseños que producen grandes pérdidas de presión para el sistema de secado, en ocasiones demandan entre 35 a 55\% de la presión que entrega el ventilador a un caudal de aire determinado, es decir, en ocasiones requieren mayor presión que la capa de granos de café. (Gutiérrez, 2008). En la Figura 5 se presenta el comportamiento de la presión estática 
contra el caudal para nueve intercambiadores de calor empleados en el secado de café en Colombia.

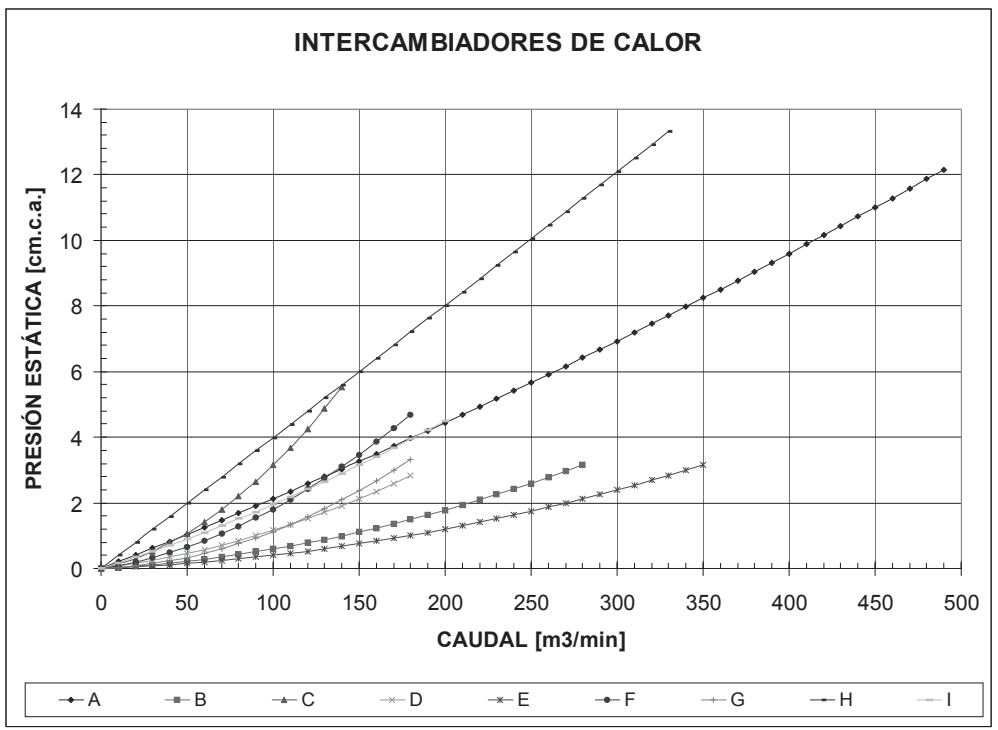

Figura 5. Curvas características de algunos intercambiadores de calor. Fuente (GUTIÉRREZ, 2008)

De los intercambiadores de calor analizados, los que presentan menores pérdidas de presión poseen baja eficiencia térmica (entre $30 \%$ a $40 \%$ ), la cual se refleja en el alto consumo de combustible incrementando los costos de secado, caso contrario de los equipos que poseen eficiencia térmica aceptable, influyendo también negativamente en el costo de secado por generar altas pérdidas de presión, que se traducen en un requerimiento de potencia mayor para el motor del ventilador, por lo que se requiere del estudio de nuevas tecnologías de intercambiadores de calor aplicables al secado de café en Colombia.

\subsection{Sistemas de combustión}

normalmente son construidos en láminas de acero para la quema de combustibles sólidos como leña, carbón o el cisco de café 
en sistemas de secado con fuego directo o indirecto. Los sistemas de fuego indirecto se componen principalmente por una cámara de combustión, puerta de abastecimiento, parrillas y ceniceros con este sistema se calienta el aire en un intercambiador de calor a las condiciones necesarias en la cámara de secado y en algunos casos se cuenta con ciclones antes de evacuar los gases de combustión por la chimenea a la atmósfera. En los secadores de fuego directo disminuye el tiempo de secado pero no utiliza intercambiador de calor ni chimenea y se calienta directamente la cámara de secado sin garantizar el no contacto de la carga a secar con los humos, obteniéndose un café de baja calidad y condiciones no aptas en el lugar del proceso como lo evidencia la Figura 6.

Estos combustibles sólidos son utilizados debido a la diferencia en precios con los combustibles derivados del petróleo bien sean líquidos o gaseosos sin importar las consecuencias sobre el medio ambiente. El "Intergovermental Panel on Climate Chance - IPCC" reporta los factores de emisión de diferentes gases de efecto invernadero para diferentes combustibles empleados en los procesos industriales de la economía mundial. En la Tabla 1 se presentan los factores de emisión de dióxido de carbono para diferentes combustibles, donde se puede evidenciar el impacto positivo al poder emplear el alcohol carburante como combustible en el proceso de beneficio en Colombia.

Es conveniente y totalmente pertinente para la región y el país la apropiación y desarrollo tecnológico de sistemas de combustión de alta eficiencia, amigable con el medio ambiente que disminuya la brecha tecnológica existente en los sistemas de generación de calor en secadores de café. 


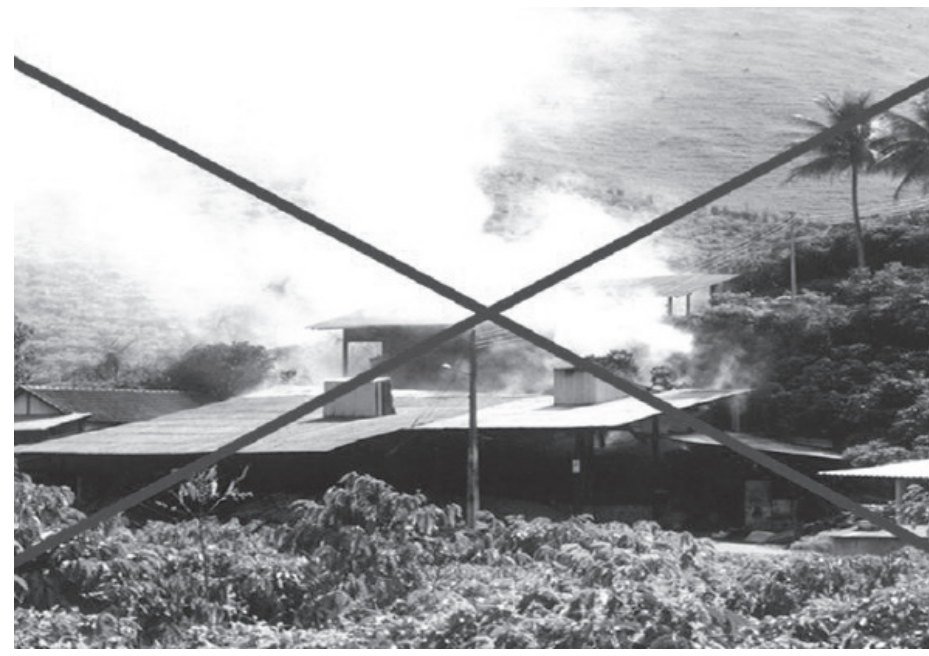

Figura 6. Secador de combustible sólido con fuego directo.

Fuente (MOULIN, 2008)

Tabla 1. FActor de EMISIÓN de CO2 PARA DifeRentes Combustibles

\begin{tabular}{|l|c|}
\hline \multicolumn{1}{|c|}{ Combustible } & $\begin{array}{c}\text { Factor de emisión } \\
\boldsymbol{t} \boldsymbol{C O}_{\mathbf{2}} / \boldsymbol{T} \boldsymbol{J}\end{array}$ \\
\hline Carbones bituminosos & 96.1 \\
\hline Carbón coque & 94.6 \\
\hline Fuel Oíl & 77.4 \\
\hline Gasolina & 69.3 \\
\hline GLP & 63.1 \\
\hline Gas natural & 56.1 \\
\hline Alcohol carburante & 2.0 \\
\hline
\end{tabular}

\section{Oportunidades de mejora en el SECAdo mecánico de} CAFÉ

el secado es la etapa con mayor participación en los costos del beneficio del café, por ello se han adelantado investigaciones con el fin de disminuir el costo de este proceso, utilizando tecnologías 
como el secador intermitente de flujos concurrentes (aire y granos), con mayor eficiencia térmica que los secadores de capa fija y con inversión de capa, utilizados actualmente en la fincas colombianas (Estévez \& Reyes, 1990; Rivera \& Vélez, 1997). Se ha evaluado el empleo de combustibles como el cisco del café, de relativo bajo costo. También se ha desarrollado tecnología para aprovechar más eficientemente la energía térmica (Buitrago, 1991; Álvarez \& Martínez, 2007) y eléctrica durante el secado y metodologías para el diseño de ventiladores con mejores especificaciones técnicas que los utilizados actualmente, generalmente fabricados en talleres veredales.

Con los esfuerzos anteriores se ha avanzado en el aprovechamiento de la energía utilizada en el secado, sin embargo, con los combustibles empleados (cisco, leña del café y carbón mineral, los más utilizados) no se ha logrado disminuir notoriamente el impacto ambiental generado por la emisión de $\mathrm{CO} 2$ y de partículas.

Con el propósito de contribuir a la disminución del costo del secado del café y al impacto ambiental generado durante el calentamiento del aire, es factible diseñar un dispositivo que utilice alcohol carburante, obtenido a partir de los subproductos del café, pulpa y mucílago. Esta nueva tecnología, además de ser innovadora, podría aprovechar el mucílago que con frecuencia en las fincas es vertido a las fuentes de agua generando graves problemas ambientales. Adicionalmente podría contribuir también a disminuir el calentamiento global.

Según (Rodríguez, 2007), el 64,31\% de la materia seca del mucílago y el $17,3 \%$ de materia seca de la pulpa son azúcares reductores y los estudios han demostrado que de $100 \mathrm{~kg}$ de café cereza, si se aprovecha la pulpa y el mucílago resultante se pueden generar 1,924 litros de etanol.

Es conveniente señalar que la producción de alcohol carburante a partir del café no implicaría en ningún caso aumentar las zonas de cultivo, por lo que la rentabilidad y sostenibilidad ambiental de este proceso no presentan riesgo adicional para la 
industria cafetera. Se calcula en 24 millones de galones por año la producción de etanol si se utilizara la totalidad del mucílago y la pulpa resultantes de exportar once o doce millones de sacos anuales de café.

Actualmente la Federación Nacional de Cafeteros de Colombia ha destinado recursos para la construcción de plantas piloto de producción de etanol, que serán ubicadas en aquellas zonas que presentan mayores índices de producción, con el objetivo de aprovechar al máximo las posibilidades del proyecto.

Cuatro décadas atrás, cuando empezó la utilización masiva de los computadores, se han usado modelos matemáticos para describir el proceso de secado y enfriamiento de los granos y desde entonces se consideran estos procesos como buenos ejemplos de la gran utilidad práctica de la simulación matemática. (Parra et al, 2008a) implementó en lenguaje de programación Microsoft Visual Basic, dos programas de simulación matemática para el secado de café, y tomó como base los modelos de Thompson (Thompson et al, 1968) y de la Universidad del Estado de Michigan (MSU) (Bakker, 1974); para ello utilizó los parámetros determinados por (Domínguez et al, 1983; Trejos, 1986; Jaramillo, 1989; Montoya, 1989; López \& Ospina, 1990; Ospina, 1990; Alzate, 1992; Montenegro, 1992; Roa et al, 1999), para la simulación matemática del secado de café pergamino. Ambos programas estiman el funcionamiento de los secadores mecánicos de café existentes en Colombia y al comparar los resultados obtenidos de la simulación, con los resultados experimentales obtenidos en Cenicafé, Figura 7, se notó que los modelos predicen adecuadamente el secado del café pergamino. 


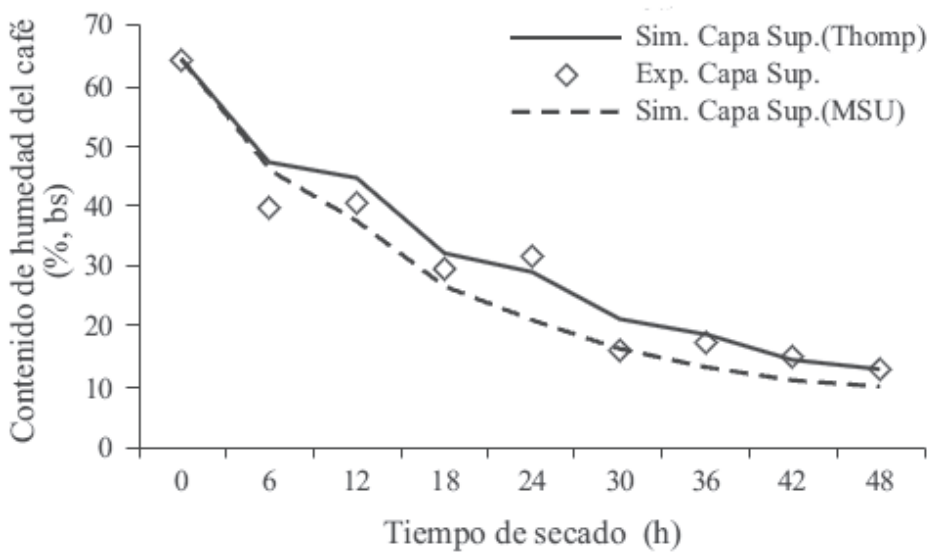

Figura 7. COMPARACIÓN DE LOS RESULTADOS OBTENIDOS EXPERIMENTALMENTE (MONTENEGRO, 1992) CON LOS OBTENIDOS POR LOS PROGRAMAS DE SIMULACIÓN DESARROLLADOS CON BASE EN LOS MOdelos DE THOMPSON Y MSU POR (PARRA ET AL, 2008A)

Con base en los resultados de la evaluación de los programas, (Parra et al, 2008b) implementó un único programa de simulación para el secado de café pergamino, llamado SECAFE, el cual fue utilizado para determinar las condiciones óptimas de operación para cada uno de los secadores mecánicos existentes y poder proporcionar recomendaciones para su manejo eficiente, con el fin de obtener café pergamino seco con un contenido de humedad final aceptado para la comercialización y predecir el tiempo de secado, la eficiencia térmica del proceso y el comportamiento del grano durante el secado.

Estos estudios previos pueden ser optimizados mediante la simulación numérica que brinda la mecánica de fluidos computacional por medio de diferentes programas entre ellos el FLUENT, que permitirá predecir el comportamiento fluido-dinámico de los diferentes sistemas del secador mecánico usando alcohol carburante como parte del proyecto "Secado de café con empleo de alcohol carburante obtenido de los subproductos del proceso de beneficio húmedo". 


\section{Conclusiones}

- El principio del secado mecánico de café consiste en calentar una corriente de aire a una temperatura promedio de $50^{\circ} \mathrm{C}$ para facilitar la transferencia de calor y masa entre los granos de café y el aire caliente, de esta forma se reduce el contenido de humedad de un $53 \%$ a un $10 \%$ en promedio. Para esto, a través de la historia se han utilizado diferentes sistemas térmicos compuestos básicamente por una cámara de secado, un ventilador, un intercambiador de calor y un sistema de combustión. En cada uno de estos subsistemas se han realizado estudios, muchos de ellos semi - empíricos y otros con mayor adelanto tecnológico, pero en cada uno de ellos es necesario seguir investigando y desarrollando tecnologías eficientes y amigables con el medio ambiente.

- Dada la necesidad mundial de utilizar fuentes de energía renovable con menores impactos ambientales, la utilización de etanol obtenido de los subproductos del proceso de beneficio húmedo del café se presenta como una buena alternativa, sin que esto implique aumentar las zonas de producción, por lo que la rentabilidad y sostenibilidad ambiental de este proceso no presentan riesgo para la industria cafetera. Estas tecnologías de aprovechamiento energético renovable aún no han sido desarrollados e implementados en Colombia por lo que se estudiando numérica y experimentalmente por parte de los autores.

\section{Bibliografía}

Alzate, J. G., 1992. Optimización operacional del silo-secador CENICAFE. Medellín: Departamento de Ingeniería Agrícola/ Universidad Nacional de Colombia. 240p. Tesis Ingeniero.

Alvarado A., G., 2004. Atributos de calidad de la semilla de café de las variedades Colombia y Tabi, Avance Técnico No.324, Cenicafé, Chinchiná-Caldas. 
Álvarez H., J.R; Martínez T., D.J., 2007. Aprovechamiento de la energía calórica de estufas campesinas para el secado del café, Avance Técnico No.366, Cenicafé, Chinchiná-Caldas.

Bakker A., F. W.; Lerew, L. E.; De Boer, S. F.; Roth, M. C., 1974. Grain drying simulation. Michigan: Research report from de Michigan State University East Lansing-MI. 80p.

Bedoya L., F., 2007. Metodología de diseño de un ventilador centrífugo utilizando programas computacionales (Excel, Inventor 7 y Visual Nastran). Pereira, Colombia: Proyecto de grado, F.I.M - U.T.P.

Buitrago, O., 1991. Implementación del secado mecánico de café en carros secadores. Bogotá: Departamento de Ingeniería Agrícola. Universidad Nacional de Colombia. 184p. Tesis Ingeniero.

Buitrago B., C.M., 2008. Medición de humedad en línea en secado mecánico de café, OK Café. Informe Anual de Actividades, Octubre de 2.007 a Septiembre de 2.008, Cenicafé, Chinchiná-Caldas.

Calle V., H., 1951. Producción de alcohol con los desperdicios del café. Cenicafé, Chinchiná-Caldas. 2(22): 33-44.

Church, A.M. 1975.Bombas y maquinas soplantes centrifugas: su teoría, cálculo, construcción y funcionamiento. La Habana, Cuba. Instituto cubano del libro.

Díaz A., A., 1994 Diseño, Construcción y Pruebas de un Ventilador Centrífugo. Pereira, Colombia: Proyecto de grado, F.I.M - U.T.P.

Domínguez, J. Parra, A.; Villa, L. G., 1983. Simulación matemática y optimización del secado de productos agropecuarios con aire natural y energía solar. Revista Ingeniería e Investigación, v.2, n.3, p.57-62.

Estévez, J. P.; Reyes, V. R., 1990. Secador por deshumidificación de aire e inversión de flujo, diseño y evaluación. Bucaramanga: Facultad de Ingeniería Mecánica. Universidad Industrial de Santander. 255p. Proyecto Grado.

Fajardo P., I.F.; Sanz U., J.R. 2004. La calidad física y el rendimiento del café en los procesos de beneficio tradicional y beneficio ecológico (Becolsub), Avance Técnico No.323, Cenicafé, ChinchináCaldas.

González, C.A., 2008. Control de temperatura y caudal de aire para optimización del secado mecánico de café. Cali, Colombia: Proyecto de grado, Universidad del Valle, Facultad de Ingeniería, 86 P. 
Gutierrez, J.M., 2008. Metodología para la construcción de ventiladores centrífugos para secado mecánico de café en talleres rurales. Pereira, Colombia: Proyecto de grado, Universidad Tecnológica de Pereira, Facultad de Ingeniería Mecánica, $122 \mathrm{P}$.

Jaramillo, B. G., 1989. Propiedades físicas del café pergamino. Bogotá: Departamento de Física. Universidad Nacional de Colombia. 190p. Tesis M.Sc.

Jurado CH., J.M., 2008. Medición de humedad en línea para secado solar Gravimet. Informe Anual de Actividades, Octubre de 2.007 a Septiembre de 2.008, Cenicafé, Chinchiná-Caldas.

López, J.; Ospina, J., 1990. Ecuación de capa delgada para el café pergamino. Cenicafé: Chinchiná. 183p. Informe de año Sabático.

Masana T., J., 1966. Ventiladores y Turbocompresores. Barcelona: Marcombo.

Montenegro, J. Y., 1992. Secador eléctrico estático para café de baja capacidad, inversión de flujo y recirculación de aire. Bogotá: Departamento de Ingeniería Agrícola. Universidad Nacional de Colombia. 161p. Tesis Ingeniero.

Montilla P., J. 2006. Caracterización de algunas propiedades físicas y factores de conversión del café. Manizales, Colombia, Universidad de Caldas. Facultad de Ciencias Agropecuarias, 107 P.

Montilla P., J.; Arcila P., J.; Aritizabal L., M.; Montoya R., E.C.; Puerta Q., G.I.; Oliveros T., C.E.; Cadena G., G. 2008a. Propiedades físicas y factores de conversión del café en el proceso de beneficio, Avance Técnico No.370, Cenicafé, Chinchiná-Caldas.

Montilla P., J.; Arcila P., J.; Aritizabal L., M.; Montoya R., E.C.; Puerta Q., G.I.; Oliveros T., C.E.; Cadena G., G. 2008b. Caracterización de algunas propiedades físicas y factores de conversión del café durante el proceso de beneficio húmedo tradicional, Artículo revista Cenicafé, 59(2):120-142, Cenicafé, Chinchiná-Caldas.

Montoya, E. C., 1989. Optimización operacional del secador intermitente de flujos concurrentes para café pergamino. Pereira: Facultad de Ingeniería Industrial. Universidad Tecnológica de Pereira, 116p. Tesis M.Sc.

Moulin, T., 2008. Estruturas e maquinários para o beneficiamento do café.

Oliveros, C.E.; Ramirez, C.A.; Sanz, J.R.; Peñuela, A.E., 2006. Secador solar de túnel para café pergamino, Avance Técnico No.353, Cenicafé, Chinchiná-Caldas. 
Oliveros, C.E.; Ramirez, C.A.; Sanz, J.R.; Peñuela, A.E., 2007. Separador hidráulico de tolva y tornillo sin fin. Avance Técnico No.360, Cenicafé, Chinchiná-Caldas.

Oliveros, C.E.; Sanz, J.R.; Ramirez, C.A.; Peñuela, A.E., 2009. Aprovechamiento eficiente de la energía en el secado mecánico del café, Avance Técnico No.380, Cenicafé, Chinchiná-Caldas.

Orozco H., C.A., 1995. Conceptos acerca del diseño de ventiladores centrífugos, Revista Scientia Et Technica No. 1. Pereira, Colombia: UTP.

Orozco H., C. A., 1996. Determinación de las curvas de comportamiento de un ventilador centrífugo a partir de datos de catálogo y de laboratorio, Revista Scientia et Technica No. 16, Pereira, Colombia: UTP.

Orozco, C.A.; Bedoya L., F., 2007. Cálculo del flujo másico y caudal de aire para un ventilador utilizado en silos para secado para del café. , Revista Scientia Et Technica No.35. Pereira, Colombia: UTP.

Osborne, W.C., 1982. Fans. England: Pergamons Press Ltd, Headington Hill Hall, Oxford OXE OBW.

Ospina, J.E., 1990. Silo Secador CENICAFE. Informe de año sabático. Federación Nacional de Cafeteros de Colombia. Chinchiná: Centro Nacional de Investigaciones de Café "Pedro Uribe Mejía". 57p.

Parra A.; Roa G.; Oliveros C.E., 2008a. SECAFÉ Parte I: Modelamiento y simulación matemática en el secado mecánico de café pergamino. Revista Brasileira de Engenharia Agrícola e Ambiental. v.12, n.4, p.415-427.

Parra A., Roa G., Oliveros, C.E., 2008b. SECAFÉ Parte II: Recomendaciones para el manejo eficiente de los secadores mecánicos de café pergamino. Revista Brasileira de Engenharia Agrícola e Ambiental. v.12, n.4, p.428-434.

Puerta G.I., 2003. Especificaciones de origen y buena calidad del café de Colombia, Avance Técnico No.316, Cenicafé, Chinchiná-Caldas.

Puerta G.I., 2006a. Buenas prácticas agrícolas para el café, Avance Técnico No.349, Cenicafé, Chinchiná-Caldas.

Puerta, G.I., 2006b. La humedad controlada del grano preserva la calidad del café, Avance Técnico No.352, Cenicafé, Chinchiná-Caldas.

Puerta, G.I., 2008a. Riesgos para la calidad y la inocuidad del café en el secado, Avance Técnico No.371, Cenicafé, Chinchiná-Caldas.

Puerta, G.I., 2008b. Riesgos para la calidad por la comercialización de café pergamino húmedo, Avance Técnico No.373, Cenicafé, Chinchiná-Caldas. 
Rivera, O.L.; Vélez P.A., 1997. Evaluación de una secadora de café de 12 arrobas (para pequeños cafeteros). Medellín: Corporación Universitaria Lasallista, Ingeniería de alimentos, 166p. Trabajo Grado.

Roa, G., Oliveros, C.E.; Álvarez, J.; Ramírez, C.A.; Sanz, J.R.; Dávila, M.T.; Álvarez, J.R.; Zambrano, D.A.; Puerta, G.I.; Rodríguez, N, 1999. Beneficio Ecológico del Café, Primera edición, Cenicafé, Chinchiná-Caldas. 160-179 P

Roa, G., 2004. "El secado solar y mecánico del café pergamino en Colombia" Reunión Nacional de Especialistas en Beneficio de Café para Unificación de Criterios sobre el Beneficio Ecológico, Cenicafé, Chinchiná, Noviembre 23-26.

Rodríguez, N., 2007. Producción de alcohol carburante a partir de los subproductos de café. Informe Anual de Actividades, Octubre de 2.006 a Septiembre de 2.007, Cenicafé, Chinchiná-Caldas. 37-50 P.

Romero, C.A., 1998. Diseño de árboles para ventiladores, Revista Scientia Et Technica No. 4. Pereira, Colombia: UTP.

Thompson, T. L.; Peart, R. M.; Foster, G. H., 1968. Mathematical simulation of corn drying - A new model. Transaction of the ASAE, v.11, n.4, p.582-586.

Trejos, R. R., 1986. Determinación de las curvas de humedad relativa de equilibrio y del calor latente de vaporización del café pergamino y trillado. Cali: Universidad del Valle, Departamento de Procesos Químicos y Biológicos, 171p. Tesis Ingeniería.

\section{Páginas de InTERnet}

J.M. Estrada S.A. Ferrería Amagá. Disponible en:

http://www.jmestradasa.com.co/e_cafe.html. Consultada en: 17/09/2009.

Máquinas Agrícolas Pinhalense. PINHALENSE. Disponible en:

http://www.pinhalense.com.br/site/espanhol/index.htm. Consultada en: 17/09/2009. 